\title{
Changes in the retrievability of associations to elements of the compound CS determine the expression of overshadowing
}

\author{
JAMES S. MILLER, JOYCE A. JAGIELO, and NORMAN E. SPEAR \\ State University of New York, Binghamton, New York
}

\begin{abstract}
In two experiments, rats were presented with a taste conditioned stimulus (CS) alone, an odor CS alone, or an odor-taste compound followed by lithium chloride injection. When tested 1 day following conditioning, there was evidence that the odor cue overshadowed conditioning to the taste; however, there was no indication of overshadowing following a longer (21-day) retention interval, despite undiminished strength of the aversion in animals conditioned with only the single element (taste). The overshadowing observed at the 1-day retention interval was not reciprocal. Rats conditioned with the odor CS alone or with the compound CS expressed odor aversions of comparable strength - that is, no overshadowing. However, in contrast to the taste aversion, overshadowing of conditioning to the odor by taste was evident following a 21-day retention interval. Rather than reflecting a failure of the overshadowed stimulus to acquire associative strength, these data suggest that overshadowing may be expressed, or not expressed, as a result of changes in the relative retrievability of learned associations over time.
\end{abstract}

When a compound conditioned stimulus (CS) made up of two separable elements (AB) is paired with an unconditioned stimulus (US), the conditioned responding elicited by the less salient element (B) is weaker than if it alone had been paired with the US. This "overshadowing" of B by A has been interpreted by major theories of Pavlovian conditioning as a failure of the overshadowed element to be associated with the US (Mackintosh, 1975, 1976; Rescorla \& Wagner, 1972). Recent evidence indicates, however, that the overshadowed stimulus may in fact become associated with the US during conditioning and that overshadowing represents a failure to express this learned association behaviorally.

A variety of studies have reported that nonreinforced presentations of the overshadowing stimulus following conditioning with a compound CS result in an enhanced level of conditioned responding to the overshadowed stimulus that may be comparable to the level observed to the more salient stimulus. This "recovery" from overshadowing, via extinction of the overshadowing stimulus, has been reported with either general activity (Kaufman \& Bolles, 1981) or suppression of drinking (Matzel, Schachtman, \& Miller, 1985; Matzel, Shuster, \& Miller, $1987)$ as the index of conditioning.

Recovery from overshadowing has also been reported as a function of an increase in the retention interval be-

This research was supported in part by a grant from the National Institute of Mental Health (1 R01 MH35219) to Norman E. Spear. The authors would like to thank Teri Tanenhaus for secretarial assistance in preparing the manuscript, and Norman Richter for drawing the figures. Requests for reprints may be addressed to Norman E. Spear, Center for Developmental Psychobiology, State University of New York at Binghamton, Binghamton, NY 13901. tween conditioning and testing. Kraemer, Lariviere, and Spear (1988) gave rats pairings of either a taste CS alone or an odor-taste compound followed by an injection of lithium chloride $(\mathrm{LiCl})$, and subsequently tested their aversion to the taste CS alone. There was clear evidence of overshadowing following a 1-day retention interval. Rats conditioned with the taste CS alone expressed significantly stronger taste aversions than did those conditioned with the odor-taste compound. When tested following a 21day retention interval, however, subjects conditioned with the taste alone or with the odor-taste compound expressed comparable aversions to the taste cue. This alleviation of overshadowing at the longer retention interval was due to an unexpected increase in the strength of the conditioned taste aversion in subjects conditioned with the compound CS; there was no significant change in the strength of the taste aversion conditioned by pairing taste alone with the US.

These results are clear in suggesting that, to at least some degree, overshadowing of the taste element does not reflect a failure in its acquisition of associative strength, but instead reflects the failure of subjects conditioned with the odor-taste compound to retrieve or express the acquired taste aversion during the ingestion test. To understand the dynamics of overshadowing - why its expression should change over time-an initial step is to compare the time-related change in response to the two elements of the compound. The expression of conditioning to the overshadowing (olfactory) component of the compound was not assessed by Kraemer et al.

In the present experiments, we examined how conditioned responding to the overshadowing element (odor, in this case) of the CS compound is affected by length of the retention interval, and how this might influence 
responding to the overshadowed component (taste, in this case). The first objective (Experiment 1) was a replication of the Kraemer et al. study that had examined tasteaversion learning in subjects conditioned with taste alone or with an odor-taste compound. The second experiment was designed to test rats with the odor component alone to determine if the overshadowing observed by Kraemer et al. was reciprocal (i.e., if odor-aversion learning was overshadowed by the taste cue and vice versa) and if it was affected by length of the retention interval.

\section{EXPERIMENT 1}

\section{Method \\ Subjects. The subjects were 75 male and female Sprague-Dawley rats, 60-75 days of age, from our breeding colony at SUNY- Binghamton. They were housed in standard wire-mesh hanging cages in a climate-controlled vivarium and were maintained on a} 16:8-h light:dark cycle with light onset at $0600 \mathrm{~h}$.

Apparatus and Materials. The taste CS was a $50 \%$ (v/v) solution of homogenized chocolate milk and water. Liquids were presented at room temperature in graduated glass cylinders fitted with metal spouts and attached to the front of each drinking cage. The odor CS consisted of $2 \mathrm{cc}$ of banana extract (Virginia Dare). Conditioning and testing took place in wire-mesh hanging cages, located in a room away from the vivarium. Animals given only the taste element as the CS were always conditioned and removed from the room before the odorant was added for conditioning of subjects in the compound-stimulus treatment conditions.

Procedure. All subjects were placed on a 23.5-h water-deprivation schedule for 7 days prior to conditioning. On the day prior to conditioning, all subjects were given a single drinking adaptation session during which they received $30 \mathrm{~min}$ of access to tap water in the conditioning/test room. On the conditioning day, subjects in the taste-CS alone condition were given 30 min access to the chocolate milk solution followed immediately by a $1 \%$ body-weight i.p. injection of either $0.3 \mathrm{M} \mathrm{LiCl}$ or an equal volume of saline. Subjects in the odor-taste condition were treated similarly, except that during presentation of the taste CS, 2 cc of banana extract was spread on paper below the front portion (location of the drinking tubes) of each drinking cage. The subjects were returned to their home cages immediately following injection of $\mathrm{LiCl}$ or saline. To assess the degree of acquired taste aversion, the rats were given $30 \mathrm{~min}$ access to the taste $\mathrm{CS}$ alone either $24 \mathrm{~h}$ or 21 days following conditioning. On the day following conditioning, subjects in the 21 day retention-interval conditions were returned to an ad-lib watering schedule until 8 days prior to testing, at which time they were returned to the 23.5 -h water-deprivation schedule.

In summary, the design comprised a $2 \times 2 \times 2$ factorial, in which rats were presented with either a taste CS alone or an odor-taste compound followed by injection of either $\mathrm{LiCl}$ or saline and tested either $24 \mathrm{~h}$ or 21 days following conditioning, yielding a total of eight independent treatment groups.

\section{Results and Discussion}

The amount of the taste CS consumed by the subjects on the conditioning day is presented in Table 1 . A $2 \times$ $2 \times 2$ ANOVA indicated that there was no significant difference between the treatment groups in the amount consumed on the conditioning day (all $F \mathrm{~s} \leq 1.02$ ). The test-day consumption of the taste CS is presented in Figure 1. A $2 \times 2 \times 2$ ANOVA indicated significant main effects of type of $\operatorname{CS}[F(1,67)=5.02, p<.05]$,
Table 1

Mean Amount of the Taste CS Consumed on the Adaptation Day and on the Conditioning Day by Subjects in Experiment 1

\begin{tabular}{|c|c|c|c|c|}
\hline \multirow{2}{*}{$\begin{array}{l}\text { Treatment } \\
\text { Condition }\end{array}$} & \multirow{2}{*}{$\begin{array}{c}\text { Retention } \\
\text { Interval } \\
\text { (in days) }\end{array}$} & \multirow{2}{*}{$\begin{array}{l}\text { Number of } \\
\text { Subjects }\end{array}$} & \multicolumn{2}{|c|}{ Consumption (in ml) } \\
\hline & & & Adaptation & Conditioning \\
\hline T-LiCl & 1 & 10 & 11.70 & 17.88 \\
\hline T-Sal & $i$ & 8 & 11.78 & 17.73 \\
\hline $\mathrm{T}-\mathrm{LiCl}$ & 21 & 10 & 12.66 & 16.58 \\
\hline T-Sal & 21 & 10 & 13.86 & 17.54 \\
\hline OT-LiCl & 1 & 10 & 11.72 & 18.00 \\
\hline OT-Sal & 1 & 8 & 11.63 & 18.75 \\
\hline OT-LiCl & 21 & 9 & 14.98 & 17.12 \\
\hline OT-Sal & 21 & 10 & 15.00 & 18.64 \\
\hline
\end{tabular}

Note- $\mathbf{T}=$ taste-alone treatment followed by either lithium chloride (LiCl) or saline (Sal) injection; OT = odor-taste compound treatment followed by either $\mathrm{LiCl}$ or Sal injection.

drug treatment $[F(1,67)=292.92, p<.01]$, and retention interval $[F(1,67)=7.40, p<.01]$. The drug treatment $\times$ retention interval interaction was also significant $[F(1,67)=8.49, p<.01]$. The remaining interactionsCS $\times$ drug $[F(1,67)<1]$, CS $\times$ retention interval $[F(1,67)=2.32]$, and CS $\times$ drug $\times$ retention interval $[F(1,67)=1.99]$-did not reach statistical significance. Pairwise comparisons were conducted using the Fisher test (Keppel, 1982), with the significance level set at $p<.05$.

These comparisons indicated that at the 1-day retention interval, subjects conditioned with either the taste alone or with the odor-taste compound consumed significantly less of the taste CS than did the subjects in their respective saline control groups. This establishes the acquisition of a conditioned taste aversion. The subjects conditioned with the taste alone consumed significantly less of the test solution than did the subjects conditioned with the odor-taste compound, however, indicating overshadowing.

At the longer (21-day) retention interval, subjects conditioned with either the taste CS alone or the odor-taste compound consumed significantly less of the taste solution than did the subjects in their respective saline control groups. In this case, however, there was no significant difference between the subjects in the two conditioned groups in the amount of the test solution consumed. The magnitude of the conditioned taste aversion expressed at the 21-day retention interval therefore was not dependent on the nature of the CS presented at conditioning; there was no overshadowing. Among subjects conditioned with the compound CS, there was a significant increase in the taste aversion (decrease in amount consumed) between those tested at the 1-day and 21-day retention intervals. The magnitude of the taste aversion expressed by the subjects conditioned with the taste CS alone was unchanged by the longer retention interval.

The results of the present experiment are comparable to those obtained by Kraemer et al. (1988). There was clear evidence of overshadowing in subjects conditioned with an odor-taste compound following a 1-day retention interval, which was not apparent at the 21-day retention 


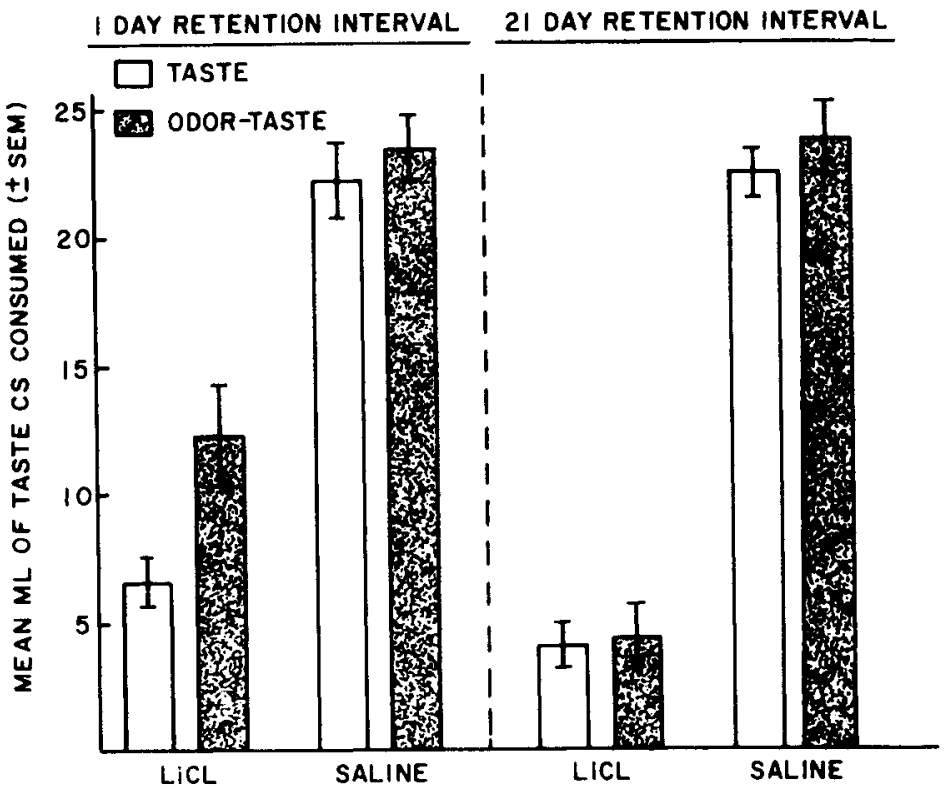

Figure 1. Mean ( $\pm S E M$ ) amount (in $\mathrm{ml}$ ) of the taste $\mathrm{CS}$ consumed by subjects presented with either the taste $C S$ alone or the odor-taste compound followed by an injection of either lithium chloride $(\mathrm{LiCl})$ or saline and tested either $24 \mathrm{~h}$ or 21 days following conditioning.

interval. This loss of overshadowing was due to an increase in the magnitude of the aversion expressed to the taste cue by the subjects conditioned with the compound $\mathrm{CS}$ at the longer retention interval.

\section{EXPERIMENT 2}

In Experiment 1, overshadowing of taste-aversion learning by the presence of an odor was evident following a short, but not a long, retention interval, suggesting that overshadowing is related to the retrieval of learned associations. In Experiment 2, we tested the magnitude of the aversion expressed to the olfactory component of the compound CS as a function of the retention interval.

\section{Method}

Subjects and Apparatus. The subjects were 43 male and female Sprague-Dawley rats, 60-75 days of age, housed as described previously. The drinking tubes and the taste and odor used as conditioned stimuli were the same as described in Experiment 1.

Procedure. All subjects were placed on a 23.5-h water-deprivation schedule for 7 days prior to conditioning. On the day prior to conditioning, all subjects were given a single drinking adaptation session during which they received $30 \mathrm{~min}$ access to tap water in the conditioning/test room. On the conditioning day, subjects in the odor-CS alone condition were given $30 \mathrm{~min}$ access to tap water with $2 \mathrm{cc}$ of banana extract beneath the front portion of the drinking cage, followed immediately by a $1 \%$ body-weight i.p. injection of either $0.3 \mathrm{M} \mathrm{LiCl}$ or an equal volume of saline. Subjects in the odor-taste condition were treated exactly as in Experiment 1. The subjects were returned to their home cages immediately following the injection of $\mathrm{LiCl}$ or saline. To assess the degree of acquired odor aversion, all subjects were given $\mathbf{3 0}$ min of access to tap water in the presence tap water in the presence of the odor CS either $24 \mathrm{~h}$ or 21 days following conditioning. On the day following conditioning, subjects in the 21-day retention-interval conditions were returned to an ad-lib watering schedule until 8 days prior to testing, at which time they were returned to the 23.5 -h water-deprivation schedule.

In summary, the design comprised a $2 \times 2 \times 2$ factorial in which the subjects were presented with either an odor CS alone or an odor-taste compound, followed by injection of either $\mathrm{LiCl}$ or saline and tested either $24 \mathrm{~h}$ or 21 days following conditioning, yielding a total of eight independent treatment groups.

\section{Results and Discussion}

The amount of liquid consumed by the subjects on the conditioning day is presented in Table 2 . A $2 \times 2 \times 2$ ANOVA indicated that there was no significant difference between the treatment groups in the amount consumed on the conditioning day (all $F \mathrm{~s}<1$ ). The results of the odor-aversion test are presented in Figure 2. A 2 $\times 2 \times 2$ ANOVA indicated a significant main effect of drug treatment $[F(1,35)=13.37, p<.01]$ and of retention interval $[F(1,35)=5.33, p<.05]$. The main effect of type of CS presentation was not significant $[F(1,35)$ $<1]$. This analysis indicated significant interactions between CS and drug treatment $[F(1,35)=6.06, p<.05]$ and between drug treatment and retention interval $[F(1,35)$ $=5.71, p<.05]$. There were no significant interactions between CS and retention interval $[F(1,35)<1]$ or among $\mathrm{CS}$, drug treatment, and retention interval $[F(1,35)=$ $1.51]$.

Pairwise comparisons (Fisher Test, as in Experiment 1) indicated that after the 1-day retention interval, subjects conditioned with either the odor CS alone or the odor-taste compound consumed significantly less on the test day than 
Table 2

Mean Amount of Liquid Consumed on the Adaptation Day and on the Conditioning Day by Subjects in Experiment 2

\begin{tabular}{lcccc}
\hline & $\begin{array}{c}\text { Retention } \\
\text { Treatment } \\
\text { Condition }\end{array}$ & $\begin{array}{c}\text { Interval } \\
\text { (in days) }\end{array}$ & $\begin{array}{c}\text { Number of } \\
\text { Subjects }\end{array}$ & \multicolumn{2}{c}{ Consumption (in ml) } \\
\cline { 4 - 5 } O-LiCl & 1 & 6 & 12.16 & Adaptation \\
O-Sal & 1 & 5 & 12.00 & Conditioning \\
O-LiCl & 21 & 6 & 12.58 & 17.17 \\
O-Sal & 21 & 5 & 12.40 & 14.67 \\
OT-LiCl & 1 & 6 & 11.67 & 17.00 \\
OT-Sal & 1 & 5 & 12.20 & 17.40 \\
OT-LiCl & 21 & 5 & 11.60 & 16.10 \\
OT-Sal & 21 & 5 & 12.20 & 17.70 \\
\hline
\end{tabular}

Note- $\mathrm{O}=$ odor-alone treatment followed by injection of either lithium chloride $(\mathrm{LiCl})$ or saline $(\mathrm{Sal})$; OT $=$ odor-taste compound followed by injection of either $\mathrm{LiCl}$ or Sal.

did those in their respective saline control groups. This established acquisition of a conditioned odor aversion by subjects in both groups. The magnitude of this aversion did not differ for subjects conditioned with the odor alone and those conditioned with the compound CS. This indicates that the taste neither overshadowed nor potentiated conditioning to the odor. There was no significant difference between the two saline control groups in consumption following the 1-day retention interval.

Following the 21-day retention interval, subjects conditioned with the odor CS alone consumed significantly less on the test day than did the subjects in their respective saline control group, indicating a significant odor aversion. The subjects conditioned with the compound $\mathrm{CS}$, however, gave no evidence of a conditioned odor aversion at this point. They consumed significantly more following the 21-day retention interval than did corresponding subjects given the odor CS alone, indicating overshadowing of the odor-aversion learning by the taste cue. There was no significant difference between the two saline groups. Although there was a tendency for the subjects conditioned with the odor CS alone to express a stronger conditioned odor aversion at the 21-day retention interval than at the 1-day retention interval, and the opposite tendency was evident in the subjects conditioned with the odor-taste compound CS, neither of the trends reached statistical significance. Finally, saline control subjects given exposure to either the odor CS alone or the compound CS and tested following a 1-day retention interval consumed significantly more on the test day than did saline control subjects in the corresponding CS presentation conditions tested following a 21-day retention interval. This suppression of drinking was apparently the result of placement into the relatively unfamiliar drinking cages following the longer retention interval, rather than the relative novelty of the odor test stimulus. Some support for this view is provided by an examination of the adaptation- and conditioning-day consumption data presented in Table 2. The consumption of water was reduced on the adaptation day (when the drinking cages were unfamiliar) relative to consumption on the conditioning day (when subjects had received adaptation to the cages but were watered in the presence of the novel odor CS). This of course can be viewed only as suggestive, since we do not have a group that provides an index of what the level of consumption of water would have been if no odorant were present on the day following adaptation. Such a comparison is available, however, from research recently completed in our laboratory (Miller, Jagielo, \& Spear, 1990). In that study, we found that on the day following adaptation, subjects watered in the presence versus the absence of an olfactory CS (2 $\mathrm{cc}$ of banana extract, as in the present study) did not differ in the amount of water consumed, indicating that the novel odor CS did not suppress drinking. This reduction in intake after the longer retention interval was not evident

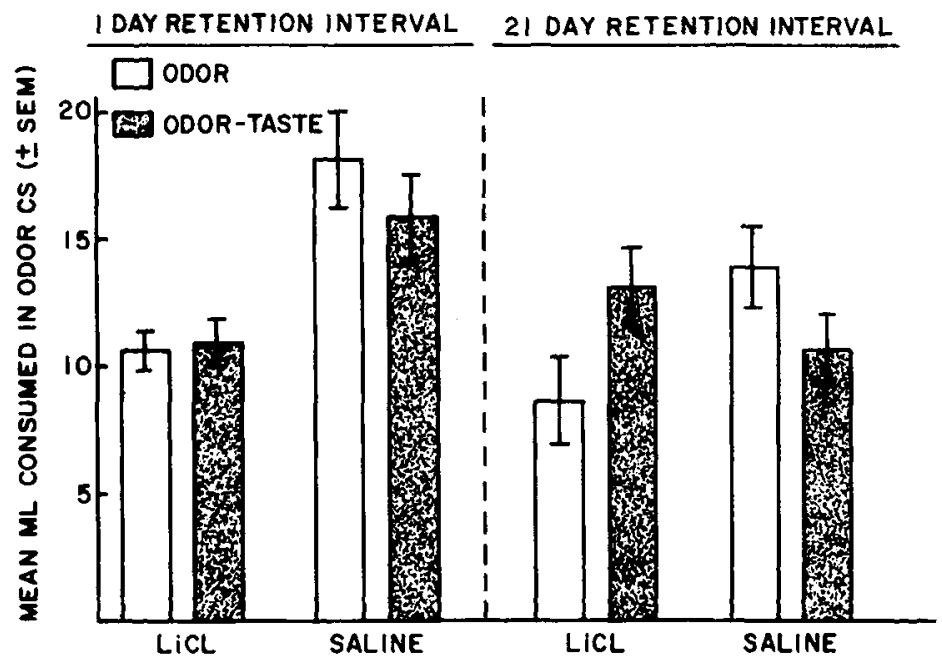

Figure 2. Mean ( $\pm S E M$ ) amount (in $\mathrm{ml}$ ) of water consumed in the presence of the odor CS by subjects presented with either the odor CS alone or the odor-taste compound followed by an injection of either lithium chloride (LiCl) or saline and tested either 24 h or 21 days following conditioning. 
in saline control subjects tested with the taste CS (Experiment 1). The subjects' greater preference for the gustatory component of the CS compound may have been sufficient to compensate for the disruption in consumption produced by the novelty of the test environment.

\section{GENERAL DISCUSSION}

In Experiment 1, there was clear evidence of overshadowing of taste-aversion learning by the presence of an olfactory cue during conditioning when subjects were tested $24 \mathrm{~h}$ following conditioning. When tested 21 days following conditioning, however, the magnitude of the conditioned taste aversion was not significantly different in subjects conditioned with the taste CS alone and those conditioned with the odor-taste compound. This loss of overshadowing of taste conditioning by odor was due to a time-dependent increase in the strength of the taste aversion in subjects conditioned with the compound CS. These results are consistent with those of Kraemer et al. (1988).

The time-dependent consequences of the aversion acquired to the olfactory component of the compound CS had a different pattern. There was equivalent expression of an acquired odor aversion by subjects conditioned with the odor CS alone and by those conditioned with the odor-taste compound when tested after the 1-day retention interval. At this point, there was no evidence that the addition of the taste cue served to overshadow or potentiate conditioning to the odor cue. Although it is clear that, under some circumstances, the presence of a taste cue may enhance or potentiate conditioning of an odor aversion (Durlach \& Rescorla, 1980; Palmerino, Rusiniak, \& Garcia, 1980; Rusiniak, Hankins, Garcia, \& Brett, 1979), potentiation is by no means an automatic consequence of pairing an odor-taste compound with $\mathrm{LiCl}$. Other tests of this effect have yielded outcomes ranging from overshadowing to no effect of the added cue (Bouton \& Whiting, 1982; Mikuka, Pitts, \& Philput, 1982; Miller, Nonneman, Kelly, Neisewander, \& Isaac, 1986).

The result of primary interest was provided by the odoraversion test that was given 21 days after conditioning. In sharp contrast to the taste aversion, for which overshadowing was observed shortly after conditioning but was lost over time, overshadowing of odor-aversion conditioning by a taste cue was not apparent shortly after conditioning but was expressed after the longer retention interval. This pattern of results suggests that subjects conditioned with the odor-taste compound CS not only had an absolute increase in accessibility of the memory for the conditioned taste aversion over time, but also had a greater increase than that which occurred for the conditioned odor aversion in the same circumstances. The stronger taste aversion expressed in terms of reduced consumption of chocolate milk after the longer retention interval was also indicated by the increased potential for the memory of the taste aversion to modulate responding to (i.e., overshadow) the olfactory element of the compound after the longer retention interval.

The complementary variation in the expression of overshadowing - either overshadowing of odor by taste or of taste by odor, depending on length of the interval between conditioning and testing-suggests that overshadowing does not indicate a failure of the overshadowed stimulus to acquire associative strength, but instead reflects variation in the retrievability or potential for activation of learned associations over time.

\section{REFERENCES}

Bouton, M. E., \& Whiting, M. R. (1982). Simultaneous odor-taste and taste-taste compounds in poison avoidance learning. Learning \& Motivation, 13, 472-494.

Durlach, P. I., Rescorla, R. A. (1980). Potentiation rather than overshadowing in flavor-aversion learning: An analysis in terms of within-compound associations. Journal of Experimental Psychology: Animal Behavior Processes, 6, 175-187.

Kaufman, M. A., Bolles, R. C. (1981). A nonassociative aspect of overshadowing. Bulletin of the Psychonomic Society, 18, 318-320.

KEPPEL, G. (1982). Design and analysis: A researcher's handbook. Englewood Cliffs, NJ: Prentice-Hall.

Kraemer, P. J., Lariviere, N. A., \& Spear, N. E. (1988). Expression of a taste aversion conditioned with an odor-taste compound: Overshadowing is relatively weak in weanlings and decreases over a retention interval in adults. Animal Learning \& Behavior, 16, 164-168.

Mackintosh, N. J. (1975). A theory of attention: Variations in the associability of stimuli with reinforcement. Psychological Review, 82 , 276-298.

MaCkintosh, N. J. (1976). Overshadowing and stimulus intensity Animal Learning \& Behavior, 4, 186-192.

Matzel, L. D., Schachtman, T. R., Miller, R. R. (1985). Recovery of an overshadowed association achieved by extinction of the overshadowing stimulus. Learning \& Motivation, 16, 398-412.

Matzel, L. D., Shuster, K., Miller, R. R. (1987). Covariation in conditioned response strength between stimuli trained in compound. Animal Learning \& Behavior, 15, 439-447.

Mikulka, P. J., Pitts, E., \& Philput, C. (1982). Overshadowing not potentiation in taste aversion conditioning. Bulletin of the Psychonomic Society, 20, 101-104.

Miller, J. S., Jagielo, J. A., \& Spear, N. E. (1990). Retrievabilit of associations to elements of the compound CS determine the expression of overshadowing. Paper presented at the annual meeting of the Eastern Psychological Association, Philadelphia.

Miller, J. S., Nonneman, A. J., Kelly, K. S., Neisewander, J. L., \& ISAAC, W. L. (1986). Disruption of neophobia, conditioned odor aversion, and conditioned taste aversion in rats with hippocampal lesions. Behavioral \& Neural Biology, 45, 240-253.

Palmerino, C. C., Rusiniak, K. W, \& Garcia, J. (1980). Flavorillness aversions: The peculiar roles of odor and taste in memory for poisons. Science, 208, 753-755.

Rescorla, R. A., W WGner, A. R. (1972). A theory of Pavlovian conditioning: Variations in the effectiveness of reinforcement and nonreinforcement. In A. H. Black \& W. F. Prokasy (Eds.), Classical conditioning: II. Current research and theory (pp. 64-99). New York Appleton-Century-Crofts.

Rusiniak, K. W., Hankins, W. G., Garcia, J., \& Brett, L. (1979). Flavor-illness aversions: Potentiation of odor by taste in rats. $B e$ havioral \& Neural Biology, 25, 1-17.

(Manuscript received May 30, 1989; revision accepted for publication July $25,1989$. .) 